Investigating the Effect of Luteolin on Interleukin-1 $\beta$ and Tumor Necrosis Factor- $\alpha$ in Inflammation Induced by Lipopolysaccharide in

\title{
Male Rats
}

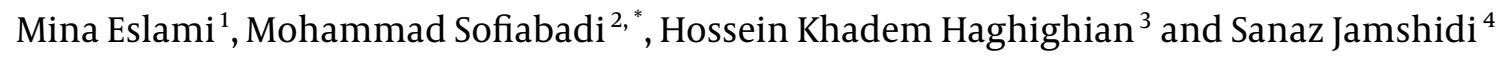 \\ ${ }^{1}$ Faculty of Health, Qazvin University of Medical Sciences, Qazvin, Iran \\ ${ }^{2}$ Department of Physiology, Qazvin University of Medical Sciences, Qazvin, Iran \\ ${ }^{3}$ Department of Nutrition Science, Faculty of Health, Qazvin University of Medical Sciences, Qazvin, Iran \\ ${ }^{4}$ Faculty of Medicine, Qazvin University of Medical Sciences, Qazvin, Iran \\ "Corresponding author: Associate Professor, Department of Physiology, Qazvin University of Medical Sciences, Qazvin, Iran. Tel: +98-2833336002, Fax: +98-2833324971, Email: \\ mohasofi@yahoo.com
}

Received 2017 July 18; Revised 2018 February 25; Accepted 2018 May 21.

\begin{abstract}
Background: Consumption of herbal flavonoids instead of chemical drugs has increased in the recent years due to fewer side effects as well as affordability.

Objectives: In this study, the effect of luteolin was investigated on inflammation induced by lipopolysaccharide in male rat's serum by measurement of the proinflammatory factors of IL-1 $\beta$ and TNF- $\alpha$.

Methods: Overall, 90 male Wistar rats weighing 180 to 200 grams were chosen and divided to control, Sham (solvent) and positive control (Dexamethasone $15 \mathrm{mg} / \mathrm{kg}$. IP) groups, and also three experimental groups received doses of 5, 15, and $30 \mathrm{mg} / \mathrm{kg}$ of luteolin, intraperitoneally. Half an hour after injecting one of these compounds, lipopolysaccharide (30 $\mu \mathrm{g} / \mathrm{kg}$. IP) was injected. Then, at 4-, 12-, and 24-hour intervals, rats were anesthetized and blood samples were taken. Serum of samples were separated by centrifuging, and then, the samples were transferred to micro-tubes and were stored at $-80^{\circ} \mathrm{C}$. Measurement of interleukin (IL)- $1 \beta$ and tumor necrosis factor (TNF)- $\alpha$ was conducted by the enzyme linked immunosorbent assay (ELISA) method. Data were analyzed using the SPSS software, version 19.

Results: Pre-injection with luteolin in $30 \mathrm{mg} / \mathrm{kg}$ dose caused a reduction in IL-1 $\beta$ at $4(\mathrm{P}<0.05)$ and 24 hours $(\mathrm{P}<0.01)$ after the LPS injection compared to the control group. Also, luteolin significantly decreased TNF- $\alpha$ level at 12 hours $(5$ and $30 \mathrm{mg} / \mathrm{kg} ; \mathrm{P}<0.05$, 0.01 , respectively) and 24 hours ( 15 and $30 \mathrm{mg} / \mathrm{kg} ; \mathrm{P}<0.05,0.01$, respectively) intervals after LPS injection. Furthermore, IL-1 $\beta$ and TNF- $\alpha$ were significantly decreased by dexamethasone injection at all three time intervals compared with the control.

Conclusions: Luteolin caused a significant reduction in IL-1 $\beta$ and TNF- $\alpha$ of serum in acute inflammation induction. This impact is close to the dexamethasone effect as an anti-inflammatory steroid drug.
\end{abstract}

Keywords: Inflammation, Luteolin, Dexamethasone, IL-1 $\beta$, TNF- $\alpha$

\section{Background}

Inflammation is a defensive response, which leads to complex processes, such as dilation of the arteries, transfusion of plasma protein from blood vessels, and summoning leukocytes to the site of inflammation. Therefore, it involves different systems of the body, such as the immune and nervous systems $(1,2)$. Inflammation promotes secretion of inflammatory mediators, such as cyclooxygenase 2 (COX-2) and pro-inflammatory cytokines, including tumor necrosis factor (TNF- $\alpha$ ) and interleukin-1 $\beta$ (IL-1 $\beta$ ) (3). Synthetic drugs and medicinal plants are considered as recommended drugs to treat inflammation (4).
Due to high cost, lack of access, and side effects of synthetic drugs, many people in the world, who live in developing countries, have turned to medicinal herbs. This has led to many researches on the positive effects of medicinal herbs on diseases (5).

Luteolin is a type of flavonoid that is found in most herbs and herbal medicines. Flavonoids are water-soluble polyphenols, which are able to protect mammalian cells from cancer and other diseases by their effect on cellular systems (6). Along with this important feature, anti-inflammatory and recuperation properties, as well as an impact on enzymes, can be taken into account for flavonoids (7). By inhibiting or inducing enzymatic sys- 
tems, they play an important role in cell division and proliferation, platelet aggregation, detoxification, and immuneinflammatory responses (8). In traditional Asian medicine, luteolin had different therapeutic roles in treating diseases, associated with oxidative damage and acute inflammation. Examples of this effect include acute lung injury, severe myocardial infarction, and hepatitis (9-11). It has been reported that luteolin inhibits acute inflammation at micro molar concentrations and does somewhat its activity by activating antioxidant enzymes, inhibiting the activation of the nuclear factor pathway, as well as suppressing inflammatory substances (9). It can also have an inductive effect on the heme-oxygenase- 1 of macrophage cells. This process leads to reduced nitric oxide production, which arises from enzyme activity of nitric oxide synthase (12). However, the complete role of luteolin in the procedure of inflammatory diseases and the whole mechanisms of operation for it still remain unknown. Cytokines are a type of protein or glycoprotein, which is soluble or attached to the cell membrane. They are known as a mediator of acute inflammatory response against the causing agent of infection, and they are important for the immune system. Interleukin-1 $\beta$ and TNF- $\alpha$ can be mentioned among cytokines being increased during acute inflammation, and they are known as a marker for determining the severity of inflammation (13). The first index of inflammation is TNF$\alpha$ (14). This pro-inflammatory cytokine plays a role in activation of phospholipase $\mathrm{A} 2$ and increases concentration of prostaglandins in inflammatory diseases (15). The exacerbation and relieving of inflammation may be determined due to the proportion of the incremental or inhibitory response of the cytokine IL- $1 \beta$ and TNF- $\alpha$ during pathological or therapeutic interventions (16). The influence of IL$1 \beta$ on the immune system and inflammatory function during infections has been proven (17). Interleukin- $\beta$ is one of the most prominent pro-inflammatory cytokines, which increases the synthesis of endothelial-bonding molecules in inflammatory cells. It also causes vasodilatation, chemotaxis, and exacerbation of inflammation in the affected areas (18). The highest production rate of interleukin- $\beta$ is reported to be by monocytes, in which, liposaccharides and lymphocyte $\mathrm{T}$ can stimulate and increase their secretion (19).

\section{Objectives}

As knowledge is limited in connection to the antiinflammatory effect of luteolin and its mechanisms, the purpose of this study was to investigate the effect of luteolin injection as an anti-inflammatory flavonoid compound found in some herbs on induced inflammation with lipopolysaccharide in male rats by measuring the proinflammatory factors of IL- $1 \beta$ and TNF- $\alpha$.

\section{Methods}

\subsection{Animals}

In this experimental study, 90 male Wistar rats (180 to $220 \mathrm{~g}$ of weight) were used. The number of samples for this study was determined based on similar studies in this field. Animals were obtained from Razi Institute (Karaj-Iran), and they were kept in standard light, noise environment, and temperature (optimal condition for the laboratory). The animals were kept in 12 hours of darkness condition. The access of animals to water and food was Ad libitum. All experiments involving animals were conducted according to the policy of Iranian Convention for the Protection of Vertebrate Animals used for Experimental Purposes, and the protocol was approved by the Ethics Committee of the Health School, Qazvin University of Medical Sciences, Qazvin, Iran (the ethics code: IR.QUMS.REC.1395.179).

\subsection{Induction of Inflammation and Sampling}

First, the rats were divided accidentally to six groups of 15, including control, Sham (normal saline), dexamethasone (15 mg/kg as the positive control group), and three groups receiving luteolin at doses of 5, 15, and $30 \mathrm{mg} / \mathrm{kg}$. During the test, luteolin powder was diluted with normal saline reaching the desired dose and it was injected in the animal's peritoneum. Half an hour later, 30 micrograms per kilogram of lipopolysaccharide was injected intraperitoneally in order to create inflammation. The rats were anesthetized at intervals of 4,12, and 24 hours after the injection of lipopolysaccharide with intraperitoneal administration of ketamine and xylazine (by $50 / 10 \mathrm{mg} / \mathrm{kg}$ ratio). Blood sampling was done through the heart of the rats. Then, blood samples were centrifuged at $4000 \mathrm{rpm}$ for 15 minutes, causing the serum to be separated. After that, the serum was transferred to the micro-tube and it was stored at $-80^{\circ} \mathrm{C}$. Concentration of IL- $1 \beta$ and TNF- $\alpha$ was measured by the ELISA method, using Uscan Commercial Company kits (USA) and its instructions.

\subsection{Statistical Analysis}

The results were expressed as mean \pm SD. The SPSS version 19 software was used for data analysis by implementing the one-way analysis of variance (ANOVA) test as well as Tukey follow-up test. The least significant difference was considered as $\mathrm{P} \leq 0.05$. 


\section{Results}

\subsection{Effect of Luteolin on Interleukin-1 $\beta$}

No significant difference was observed between the control and sham (solvent) groups in any of the time intervals for measuring the pro-inflammatory factors. Therefore, for ease of data expression, the results of the sham group are not presented.

As shown in Figure 1, injection of polyphenol substance of luteolin at concentrations of 5,15 , and $30 \mathrm{mg} / \mathrm{kg}$ or dexamethasone $(15 \mathrm{mg} / \mathrm{kg})$ as a standard common antiinflammatory drug caused a reduction in secretion of inflammatory prognostic factor IL-1 $\beta$ at three different time intervals of 4,12 , and 24 hours after the injection of lipopolysaccharide. There was a significant difference within four hours of injection in the effect of decreasing IL-1 $\beta$ in the groups receiving dexamethasone and luteolin with a concentration of $30 \mathrm{mg} / \mathrm{kg}$ compared to the control group (both $\mathrm{P}<0.05$ ). Within 12 hours of lipopolysaccharide injection, luteolin level was reduced at each of the three used concentrations compared to the control group, yet this difference was not significant. However, dexamethasone inhibited the increase of IL-1 $\beta$, significantly ( $\mathrm{P}<0.001)$. Twenty-four hours after the injection of lipopolysaccharide, injection of luteolin or dexamethasone at concentrations of 15 and $30 \mathrm{mg} / \mathrm{kg}$ caused reduction of IL-1 $\beta$ secretion significantly compared with the control group $(\mathrm{P}<0.01)$ (Figure 1$)$.

\subsection{Effect of Luteolin on Tumor Necrosis Factor- $\alpha$}

Within four hours after the injection of lipopolysaccharide, luteolin caused a decrease in serum level of TNF- $\alpha$ (as an inflammatory marker) yet this was not significant. The inhibitory effect of dexamethasone on TNF- $\alpha$ was significant compared with the control group $(\mathrm{P}<0.05)$. Within 12 hours of injection, injection of luteolin at concentrations of $5 \mathrm{mg} / \mathrm{kg}(\mathrm{P}<0.05)$ and $30 \mathrm{mg} / \mathrm{kg}(\mathrm{P}<0.01)$ or dexamethasone $(\mathrm{P}<0.01)$ caused a significant decrease in TNF- $\alpha$ serum levels. Within 24 hours of lipopolysaccharide injection, luteolin at all three used concentrations prevented the increase of TNF- $\alpha$ serum levels, in which, the differences were significant at concentrations of 15 and $30 \mathrm{mg} / \mathrm{kg}$ $(\mathrm{P}<0.01)$ compared to the control group. The greatest inhibitory effect of luteolin was acquired at a dose of 30 $\mathrm{mg} / \mathrm{kg}$. Furthermore, dexamethasone injection led to a decrease in the serum level of TNF- $\alpha$ in comparison with the control group (Figure 2).

\section{Discussion}

The results of the present study showed that the prescription of luteolin at all three used concentrations has impressive inhibitory effect on the amount of IL-1 $\beta$ and TNF- $\alpha$ serum level following the administration of LPS. This effect is almost dose-dependent and its anti-inflammatory effects increase with augmentation of the concentration. Luteolin at a concentration of $30 \mathrm{mg}$ indicated the most anti-inflammatory effect, which was close to the effect of steroid anti-inflammatory drug, dexamethasone. Inflammation, especially its chronic type, causes many clinical problems. For this reason, extensive and complex research has been done in this area despite the diversity in the treatment of inflammation and new ways are discovered (20). The results of this study are in line with the outcomes of studies by other researchers in this area.

For example, the anti-inflammatory and anti-itching effects of luteolin from the leaves of Perila plant was studied by Jeon et al. in 2014 through the analysis of active substances present in these leaves using high-performance liquid chromatography (HPLC) and isolating luteolin. They showed that luteolin, as the main agent, can inhibit the secretion of inflammatory cytokines IL-1 $\beta$ and TNF- $\alpha$ from human mast-cells (21).

The anti-inflammatory and anti-oxidant effects of luteolin against the acute pancreatitis were also examined through stimulation of hemeoxygenase-1 via intraperitoneal injection of cerulean and lipopolysaccharides by Xiong et al. in 2016 by creating inflammation, staining by hematoxylin and eosin, and pathological evaluation of pancreatic tissues. It was reported that pretreatment with luteolin prevents acute pancreatitis by stimulating heme oxygenase-1 through suppressing the NF-KB route in comparison with the control group of rats (22).

In addition, it was stated by Xia et al. that luteolin has significant anti-inflammatory effects in autoimmune thyroiditis (Hashimoto Disease) by reducing the phosphorylation of transcriptional activating signals (STAT3) (23). In the same field, the effect of luteolin at a higher dose than the current study was investigated and observed by Kanai et al. in 2016 on inflammation of the iris induced by endotoxin. They observed that prescription of luteolin significantly reduced the number of inflammatory cells, TNF- $\alpha$ levels, nitric oxide and prostaglandin E2 in aqueous humor (24).

In other researches, the effect of lipopolysaccharide toxicity was examined by measuring the expression and pro-inflammatory molecules of TNF- $\alpha$ and intercellular adhesion molecule-1 (ICAM-1) in response to lipopolysaccharide in the presence of luteolin or without luteolin. It was reported that luteolin inhibits the expression of pro-inflammatory molecules and protects rats against lipopolysaccharide (25). Overall, all these findings are consistent with the outcomes of the present research.

Flavonoids have many beneficial effects, including 


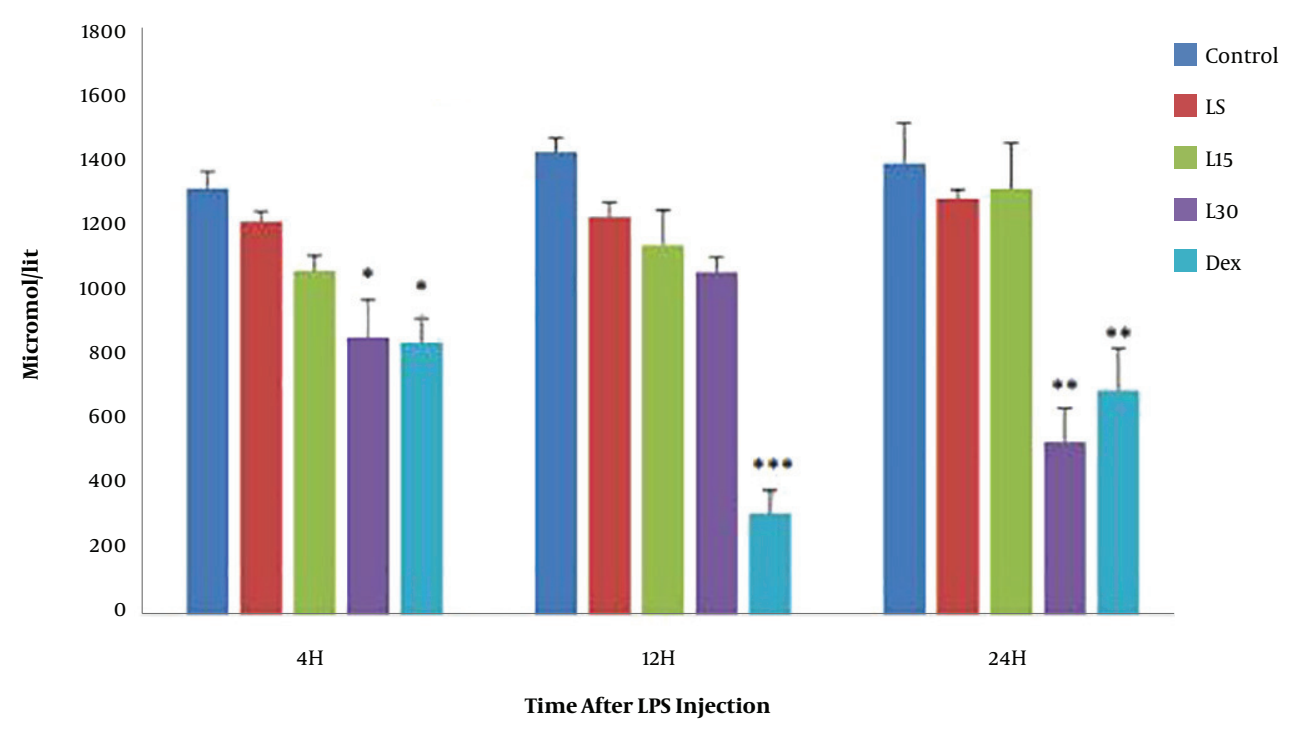

Figure 1. Average serum level of IL-1 $\beta$ at the time intervals of 4,12, and 24 hours after the intraperitoneal injection of luteolin at a dose of 15 and 30 mg/kg or dexamethasone $(15 \mathrm{mg} / \mathrm{kg})$.

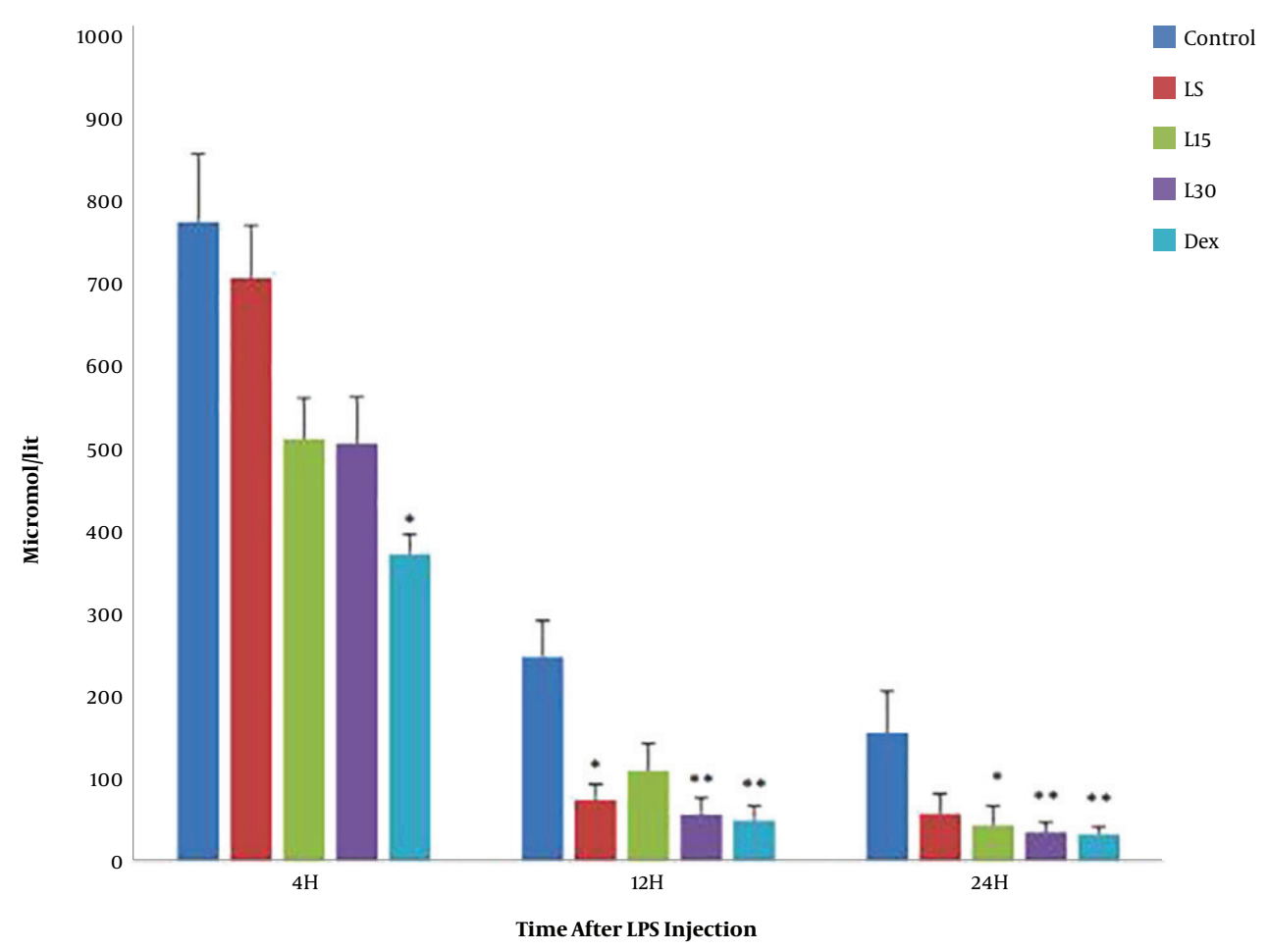

Figure 2. Average TNF- $\alpha$ concentration at time intervals of 4,12 , and 24 hours, respectively, from intraperitoneal injection at doses of 15 and $30 \mathrm{mg} / \mathrm{kg}$ of luteolin or dexamethasone $(15 \mathrm{mg} / \mathrm{kg})$.

anti-inflammatory function $(26,27)$. During an inflammatory process, immune cells, especially mast-cells, are activated and inflammatory cytokines, such as IL-1 $\beta$, TNF- $\alpha$, as well as inflammatory mediators, such as histamine, leukotrienes, serotonin, and prostaglandin E2 are released (28-30). Flavonoids with different mechanisms, such as in- 
hibition of the activity of protein kinase C, Phospholipase A2, and phosphodiesterase enzymes, which are involved in inducing inflammation, significantly reduce acute inflammatory symptoms (31). The use of luteolin in patients with MS decreases inflammation by inhibition of activated leukocytes in blood circulation and imposes its therapeutic effects (32).

It has also been reported that Luteolin inhibits the production of inflammatory mediators and proinflammatory cytokines by blocking the NF-KB signaling pathway in fibroblasts and macrophages. In addition, it suppresses the expression of genes involved in inflammation. Overall, all these factors help reduce inflammation (33-35). Luteolin is effective on induction of heme oxygenase-1 by inhibition of STAT1 and STAT3 phosphorylation and regulation of the $\mathrm{Nrf}_{2}$ (36). For example, it can inhibit synthase of cyclooxygenase-2 and nitric oxide (iNOS). It can also inhibit the production of nitric oxide (NO) in the intestine by controlling the JAK / STAT pathway (37). This flavonoid protects the heart and improves cardiac function by suppressing the P38 MAPK route (38). According to all the information, in the current study, luteolin inhibitory mechanism of action on TNF- $\alpha$ and IL-1 $\beta$ production, and thereby reducing inflammation, may be due to the activation of one or more of the mentioned mechanisms. Luteolin is found in a number of plants and a considerable amount exists in celery, green peppers, and chamomile tea (39). Further studies are required to fully understand the mechanism of its anti-inflammatory effect.

\section{Acknowledgments}

The authors would like to thank the research deputy of Qazvin University of Medical Sciences for their financial support.

\section{Footnotes}

Conflict of Interests: The authors declare that there was no conflict of interest regarding the publication of this paper.

Funding/Support: This research was financially supported by the Health Faculty of Qazvin University of Medical Sciences. This article was the result of a research project contract, No: 688.

\section{References}

1. Scheller J, Chalaris A, Schmidt-Arras D, Rose-John S. The pro- and anti-inflammatory properties of the cytokine interleukin-6. Biochim Biophys Acta. 2011;1813(5):878-88. doi: 10.1016/j.bbamcr.2011.01.034. [PubMed: 21296109].
2. Kupeli E, Tatli II, Akdemir ZS, Yesilada E. Estimation of antinociceptive and anti-inflammatory activity on Geranium pratense subsp. finitimum and its phenolic compounds. J Ethnopharmacol. 2007;114(2):234-40. doi: 10.1016/j.jep.2007.08.005. [PubMed: 17904777].

3. Jackson S, Elali A, Virgintino D, Gilbert MR. Blood-brain barrier pericyte importance in malignant gliomas: What we can learn from stroke and Alzheimer's disease. Neuro Oncol. 2017;19(9):1173-82. doi: 10.1093/neuonc/nox058. [PubMed: 28541444]. [PubMed Central: PMC5570196].

4. Lipsky PE. Interleukin-6 and rheumatic diseases. Arthritis Res Ther. 2006;8 Suppl 2. S4. doi: 10.1186/ar1918. [PubMed: 16899108]. [PubMed Central: PMC2946778].

5. Das K, Tiwari RK, Shrivastava DK. Techniques for evaluation of medicinal plant products as antimicrobial agent: Current methods and future trends. J Med Plant Res. 2010;4(2):104-11.

6. Arun KG, Sharanya CS, Sandeep PM, Sadasivan C. Inhibitory activity of hibifolin on adenosine deaminase- experimental and molecular modeling study. Comput Biol Chem. 2016;64:353-8. doi: 10.1016/j.compbiolchem.2016.08.005. [PubMed: 27591790].

7. Napoleone E, Cutrone A, Zurlo F, Di Castelnuovo A, D'Imperio M, Giordano L, et al. Both red and blond orange juice intake decreases the procoagulant activity of whole blood in healthy volunteers. Thromb Res. 2013;132(2):288-92. doi: 10.1016/j.thromres.2013.06.022. [PubMed: 23859487].

8. Liu RH. Health-promoting components of fruits and vegetables in the diet.Adv Nutr.2013;4(3):384S-92S. doi:10.3945/an.112.003517. [PubMed: 23674808]. [PubMed Central: PMC3650511].

9. Seelinger G, Merfort I, Schempp CM. Anti-oxidant, anti-inflammatory and anti-allergic activities of luteolin. Planta Med. 2008;74(14):166777. doi: 10.1055/s-0028-1088314. [PubMed: 18937165].

10. Kuo MY, Liao MF, Chen FL, Li YC, Yang ML, Lin RH, et al. Luteolin attenuates the pulmonary inflammatory response involves abilities of antioxidation and inhibition of MAPK and NFkappaB pathways in mice with endotoxin-induced acute lung injury. Food Chem Toxicol. 2011;49(10):2660-6. doi: 10.1016/j.fct.2011.07.012. [PubMed: 21782879].

11. Nabavi SF, Braidy N, Gortzi O, Sobarzo-Sanchez E, Daglia M, SkalickaWozniak K, et al. Luteolin as an anti-inflammatory and neuroprotective agent: A brief review. Brain Res Bull. 2015;119(Pt A):1-11. doi: 10.1016/j.brainresbull.2015.09.002. [PubMed: 26361743].

12. Sung J, Lee J. Anti-inflammatory activity of butein and luteolin through suppression of NFkappaB activation and induction of heme oxygenase-1. J Med Food. 2015;18(5):557-64. doi: 10.1089/jmf.2014.3262. [PubMed: 25692285].

13. Kim HJ, Lee W, Yun JM. Luteolin inhibits hyperglycemia-induced proinflammatory cytokine production and its epigenetic mechanism in human monocytes. Phytother Res. 2014;28(9):1383-91. doi: 10.1002/ptr.5141. [PubMed: 24623679].

14. Hall BE, Zhang L, Sun ZJ, Utreras E, Prochazkova M, Cho A, et al. Conditional TNF-alpha overexpression in the tooth and alveolar bone results in painful pulpitis and osteitis. J Dent Res. 2016;95(2):188-95. doi: 10.1177/0022034515612022. [PubMed: 26503912]. [PubMed Central: PMC4720955].

15. Lin CC, Lin WN, Cho RL, Wang CY, Hsiao LD, Yang CM. TNFalpha-induced cPLA2 expression via NADPH oxidase/reactive oxygen species-dependent NF-kappaB cascade on human pulmonary alveolar epithelial cells. Front Pharmacol. 2016;7:447. doi: 10.3389/fphar.2016.00447. [PubMed: 27932980]. [PubMed Central: PMC5122718].

16. Wahab S, Hussain A. Cytokines as targets for immunomodulation. Int J Pharm Pharm Sci. 2013;5(3):60-4.

17. Singh D, Aggarwal A, Maurya R, Naik S. Withania somnifera inhibits NF-kappaB and AP-1 transcription factors in human peripheral blood and synovial fluid mononuclear cells. Phytother Res. 2007;21(10):90513. doi: 10.1002/ptr.2180. [PubMed:17562568]. 
18. Hakkinen L, Larjava H, Fournier BP. Distinct phenotype and therapeutic potential of gingival fibroblasts. Cytotherapy. 2014;16(9):117186. doi: 10.1016/j.jcyt.2014.04.004. [PubMed: 24934304].

19. Sorensen LK, Havemose-Poulsen A, Bendtzen K, Holmstrup P. Aggressive periodontitis and chronic arthritis: Blood mononuclear cell gene expression and plasma protein levels of cytokines and cytokine inhibitors. J Periodontol. 2009;80(2):282-9. doi: 10.1902/jop.2009.080347. [PubMed: 19186969].

20. Khalili M, Sahraee H, Hassanpour Ezati M. Anti-inflammatory effect of alcoholic stinging nettle extract in male nmri rats.J Med Plant Res. 2007;2(22):46-53.

21. Jeon IH, Kim HS, Kang HJ, Lee HS, Jeong SI, Kim SJ, et al. Antiinflammatory and antipruritic effects of luteolin from Perilla (P. frutescens L.) leaves. Molecules. 2014;19(6):6941-51. doi: 10.3390/molecules19066941. [PubMed: 24871572]. [PubMed Central: PMC6271665].

22. Xiong J, Wang K, Yuan C, Xing R, Ni J, Hu G, et al. Luteolin protects mice from severe acute pancreatitis by exerting HO-1-mediated antiinflammatory and antioxidant effects. Int J Mol Med. 2017;39(1):113-25. doi: 10.3892/ijmm.2016.2809. [PubMed: 27878246]. [PubMed Central: PMC5179180].

23. Xia N, Chen G, Liu M, Ye X, Pan Y, Ge J, et al. Anti-inflammatory effects of luteolin on experimental autoimmune thyroiditis in mice. Exp Ther Med. 2016;12(6):4049-54. doi: 10.3892/etm.2016.3854. [PubMed: 28101184]. [PubMed Central: PMC5228320].

24. Kanai K, Nagata S, Hatta T, Sugiura Y, Sato K, Yamashita Y, et al. Therapeutic anti-inflammatory effects of luteolin on endotoxininduced uveitis in Lewis rats. J Vet Med Sci. 2016;78(8):1381-4. doi: 10.1292/jvms.16-0196. [PubMed: 27170432]. [PubMed Central: PMC5053947].

25. Kotanidou A, Xagorari A, Bagli E, Kitsanta P, Fotsis T, Papapetropoulos A, et al. Luteolin reduces lipopolysaccharide-induced lethal toxicity and expression of proinflammatory molecules in mice. Am J Respir Crit Care Med. 2002;165(6):818-23. doi: 10.1164/ajrccm.165.6.2101049. [PubMed: 11897650].

26. Choi CW, Jung HA, Kang SS, Choi JS. Antioxidant constituents and a new triterpenoid glycoside from Flos Lonicerae. Arch Pharm Res. 2007;30(1):1-7. doi: 10.1007/BF02977770. [PubMed:17328234].

27. Mehrbani M, Choopani R, Fekri A, Mehrabani M, Mosaddegh M, Mehrabani M. The efficacy of whey associated with dodder seed extract on moderate-to-severe atopic dermatitis in adults: A randomized, double-blind, placebo-controlled clinical trial.JEthnopharmacol. 2015;172:325-32. doi: 10.1016/j.jep.2015.07.003. [PubMed: 26151244].

28. Hosoda M, Yamaya M, Suzuki T, Yamada N, Kamanaka M, Sekizawa $\mathrm{K}$, et al. Effects of rhinovirus infection on histamine and cytokine production by cell lines from human mast cells and basophils. I Immunol. 2002;169(3):1482-91. doi: 10.4049/jimmunol.169.3.1482. [PubMed: 12133975].
29. Kurashima Y, Kiyono H. New era for mucosal mast cells: Their roles in inflammation, allergic immune responses and adjuvant development. Exp Mol Med. 2014;46. e83. doi: 10.1038/emm.2014.7. [PubMed: 24626169]. [PubMed Central: PMC3972796].

30. Kim HI, Hong SH, Ku JM, Kang S, Kim TY, Shin YC, et al. Tonggyutang, a traditional Korean medicine, suppresses pro-inflammatory cytokine production through inhibition of MAPKand NF-kappaB activation in human mast cells and keratinocytes. BMC Complement Altern Med.2017;17(1):186. doi:10.1186/s12906-017-1704-5. [PubMed: 28359265]. [PubMed Central: PMC5374729].

31. Zhang H, Tsao R. Dietary polyphenols, oxidative stress and antioxidant and anti-inflammatory effects. Curr Opinion Food Sci. 2016;8:3342. doi: 10.1016/j.cofs.2016.02.002.

32. Theoharides TC. Luteolin as a therapeutic option for multiple sclerosis. I Neuroinflammation. 2009;6:29. doi: 10.1186/1742-2094-6-29. [PubMed: 19825165]. [PubMed Central: PMC2768692].

33. Chan BC, Hon KL, Leung PC, Sam SW, Fung KP, Lee MY, et al. Traditional Chinese medicine for atopic eczema: PentaHerbs formula suppresses inflammatory mediators release from mast cells. J Ethnopharmacol. 2008;120(1):85-91. doi: 10.1016/j.jep.2008.07.034. [PubMed: 18725279].

34. Gangwar RS, Landolina N, Arpinati L, Levi-Schaffer F. Mast cell and eosinophil surface receptors as targets for anti-allergic therapy. Pharmacol Ther. 2017;170:37-63. doi: 10.1016/j.pharmthera.2016.10.010. [PubMed: 27773785].

35. Kang OH, Choi JG, Lee JH, Kwon DY. Luteolin isolated from the flowers of Lonicera japonica suppresses inflammatory mediator release by blocking NF-kappaB and MAPKs activation pathways in HMC1 cells. Molecules. 2010;15(1):385-98. doi: 10.3390/molecules15010385. [PubMed: 20110898]. [PubMed Central: PMC6257122].

36. Liu CW, Lin HW, Yang DJ, Chen SY, Tseng JK, Chang TJ, et al. Luteolin inhibits viral-induced inflammatory response in RAW264.7 cells via suppression of STAT1/3 dependent NF-kappaB and activation of HO-1. Free Radic Biol Med. 2016;95:180-9. doi: 10.1016/j.freeradbiomed.2016.03.019. [PubMed: 27016074].

37. Nunes C, Almeida L, Barbosa RM, Laranjinha J. Luteolin suppresses the JAK/STAT pathway in a cellular model of intestinal inflammation. Food Funct. 2017;8(1):387-96. doi: 10.1039/c6fo01529h. [PubMed: 28067377].

38. Zhu S, Xu T, Luo Y, Zhang Y, Xuan H, Ma Y, et al. Luteolin enhances sarcoplasmic reticulum Ca2+-ATPase activity through p38 MAPK signaling thus improving rat cardiac function after ischemia/reperfusion. Cell Physiol Biochem. 2017;41(3):999-1010. doi: 10.1159/000460837. [PubMed: 28222421].

39. Park CM, Song YS. Luteolin and luteolin-7-O-glucoside inhibit lipopolysaccharide-induced inflammatory responses through modulation of NF-kappaB/AP-1/PI3K-Akt signaling cascades in RAW 264.7 cells. Nutr Res Pract. 2013;7(6):423-9. doi: 10.4162/nrp.2013.7.6.423. [PubMed: 24353826]. [PubMed Central: PMC3865263]. 